\title{
THE HISTOGENESIS OF PRIMARY HEPATIC CARCINOMA
}

\author{
BY \\ I. P. BESWICK AND G. B. D. SCOTT \\ From the Department of Morbid Anatomy, Royal Free Hospital School of Medicine, London
}

(RECEIVED FOR PUBLICATION JULY 8, 1957)

The existence of hepatocellular and cholangiocellular carcinomata, arising from liver cells and bile duct epithelium respectively, has long been recognized, although the proportions of each type have varied in different series.

Gustafson (1937) reported 39 liver cell and 11 bile duct tumours amongst 62 cases of primary liver carcinoma based on 24,400 necropsies, and Wilbur, Wood, and Willett (1944) described 45 hepatomas and four cholangiomas. This predominance of liver cell tumours is also stressed by Counseller and McIndoe (1926), Loesch (1939), and Hoyne and Kernohan (1947). On the other hand, Fried (1924) described four cholangiomas and one hepatoma, while Karsner (1911) and Cunningham (1943) reported a preponderance of cholangiomas.

The existence of a combined tumour, consisting of hepatocellular and cholangiocellular elements, has been postulated comparatively recently. Milne (1909) and Beattie and Donaldson (1912) only recognized two types, while Pirie (1921) reported five tumours of doubtful or mixed origin amongst 36 cases of primary hepatic carcinoma. Gustafson (1937) described two cases of "intermediate or dual origin " in his series and this combined carcinoma has also been described by Warvi (1944).

Allen and Lisa (1949), reporting five cases of combined liver cell and bile duct tumours amongst 35 cases of primary hepatic carcinoma, described three possible combinations, namely, separate hepato- and cholangiocellular tumours in the same liver, separate tumours which intermingle, and individual masses which display both features so intimately associated that they can only be interpreted as arising from the same site. Three of their cases fell within the last group, while Campbell (1949) described four examples of mixed tumour amongst 22 cases of spontaneous hepatocellular and cholangiocellular carcinoma in ducks.

The occurrence of three apparently mixed hepato- and cholangiocellular tumours in an un- selected series of eight primary hepatic carcinomata in an undergraduate teaching museum is of interest, and histological examination of this series is considered to throw light on the question of the histogenesis of hepatic carcinomata.

\section{Necropsy Summaries}

Case 1.-Female aged 85 years. Death from congestive cardiac failure, due to coronary atheroma, myocardial fibrosis, and essential hypertension.

Liver.-Weight 4,825 g. The right lobe was almost entirely replaced by a large, lobulated bile-stained tumour showing necrosis and haemorrhage. The left lobe contained multiple small tumour nodules and the remaining liver tissue was cirrhotic. Many pulmonary metastases were present.

Microscopically the tumour was a well-differentiated hepatocellular carcinoma. The tumour cells closely resembled those of normal liver and were arranged in columns and trabeculae (Fig. 1). In piaces they were gathered into irregular lobules, surrounded by fibrous tissue, and bile could be seen.

Case 2.-Male aged 67 years. Death from cerebral haemorrhage due to cerebral atheroma.

Liver.-Weight not known, but the organ was considerably reduced in size and was cirrhotic. The right lobe contained a single rounded tumour, $5 \mathrm{~cm}$. in diameter, showing necrosis and haemorrhage.

Microscopically the tumour was a moderately well differentiated hepatocellular carcinoma, composed of small irregular polyhedral cells arranged in solid masses. Occasional tumour giant cells were present and the stroma was scanty.

Case 3.-Male aged 62 years. Death from liver failure.

Liver.-Weight not known, but the organ was greatly increased in size. The right lobe contained a circumscribed lobulated mass of pale tumour, while smaller tumour masses were present throughout the remainder of the right lobe and the whole of the left lobe. No cirrhosis was present. The right hepatic vein was blocked by tumour and there were numerous pulmonary metastases. Microscopically the tumour was a poorly differentiated hepatocellular carcinoma. 


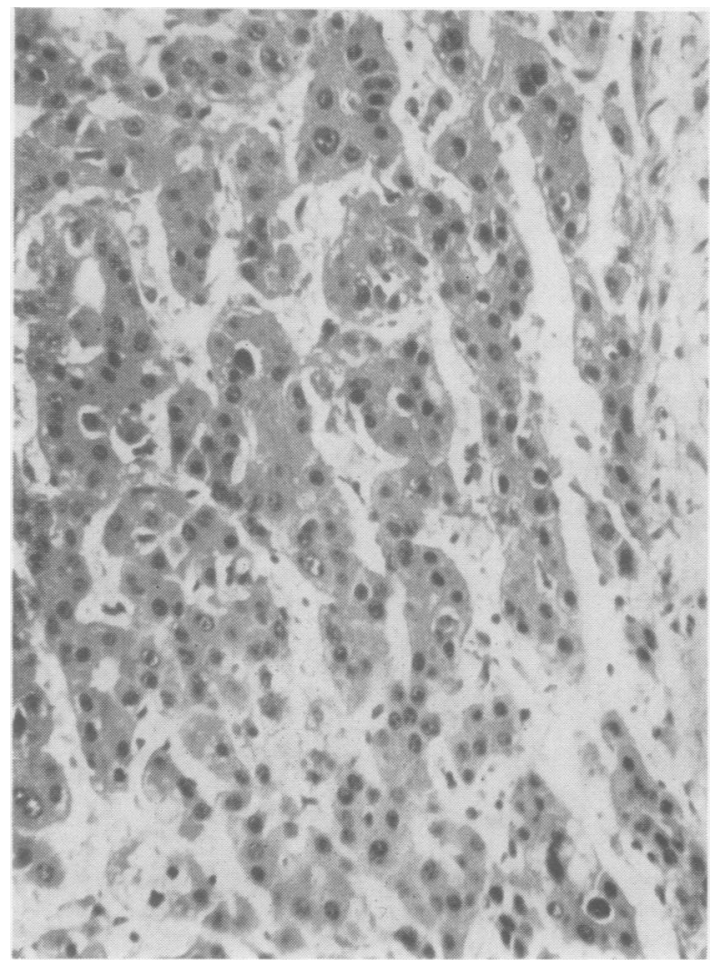

FIG. 1.-Case 1: Well-differentiated hepatocellular carcinoma showing bile. Haematoxylin and eosin $\times 200$.

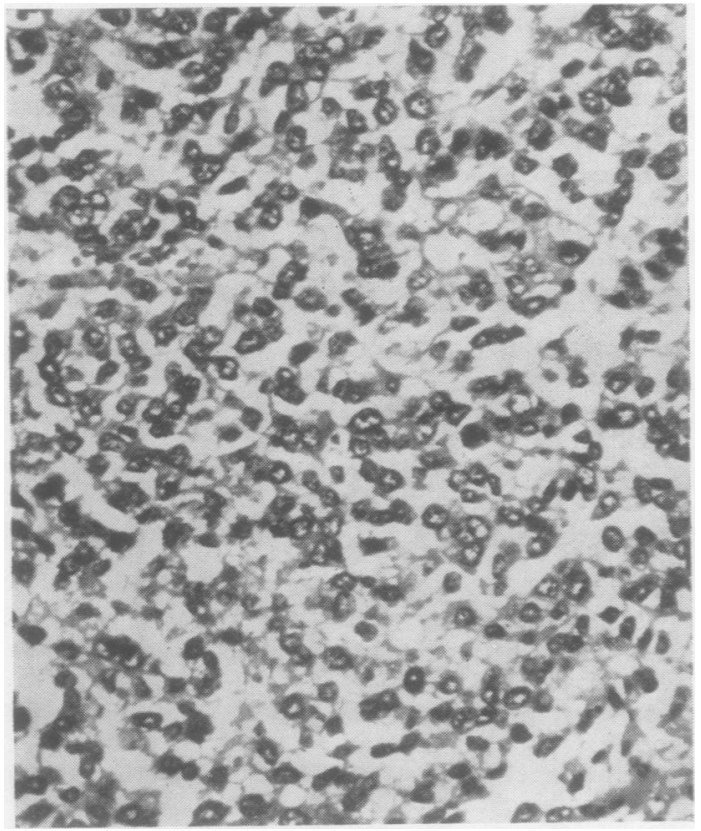

Fig. 3.-Case 4: Anaplastic carcinoma. Haematoxylin and eosin 200.

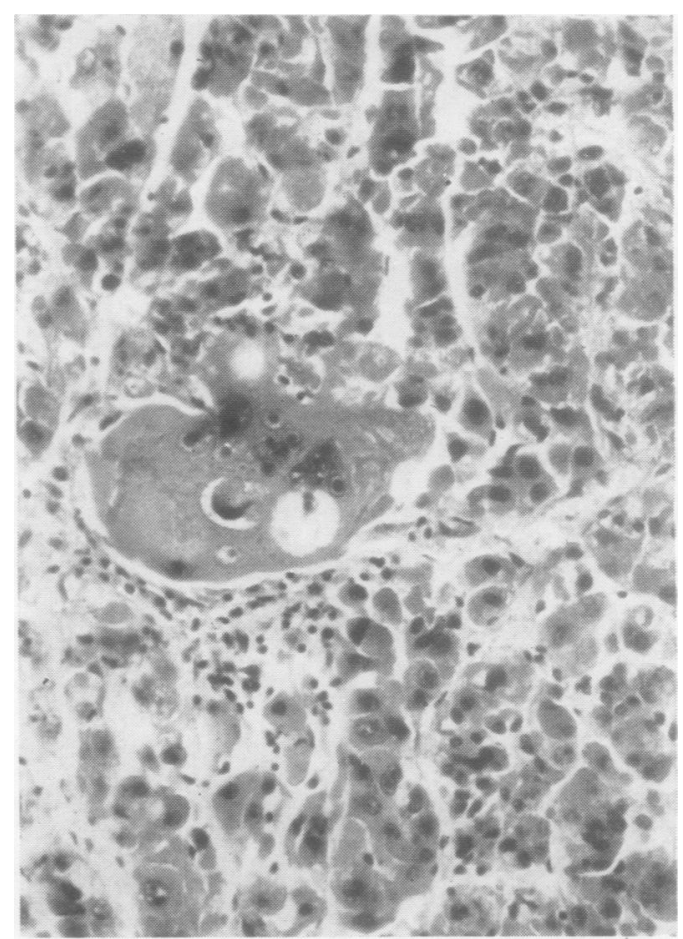

FIG. 2.-Case 3: Poorly differentiated hepatocellular carcinoma with tumour giant cells. Haematoxylin and eosin 200.

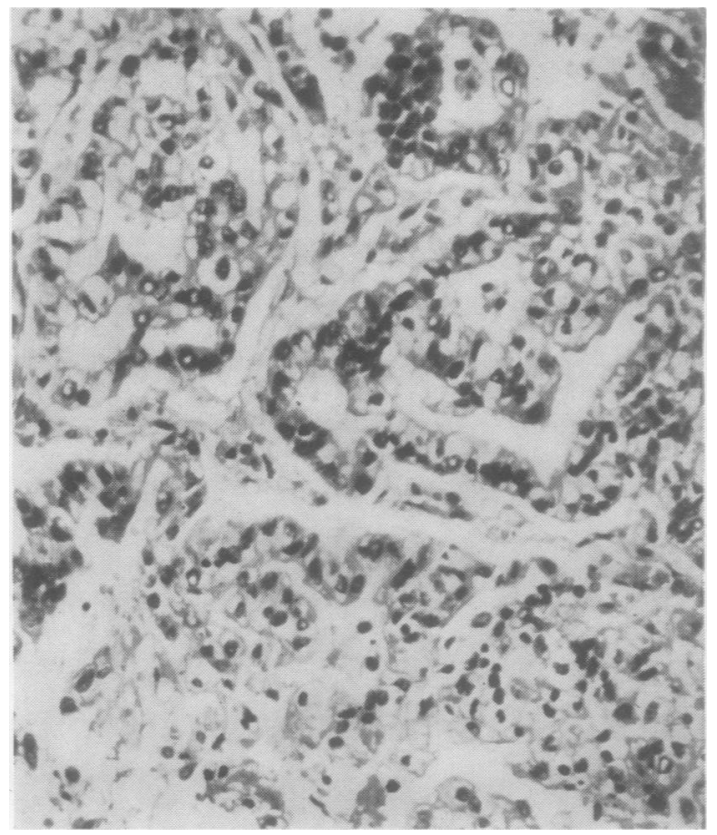

FIG. 4.-Case 4: Area with cholangiomatous appearance. Haematoxylin and eosin . 200. 


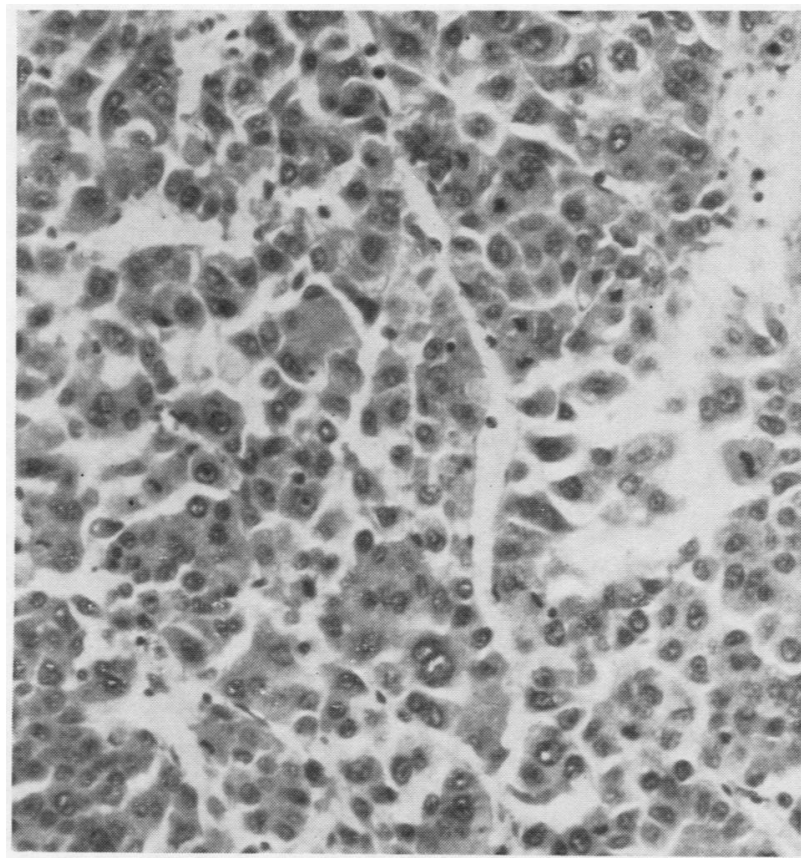

FIG. 5.-Case 5: Undifferentiated hepatocellular carcinoma. Maematoxylin and $e \sin \times 200$

The cells tended to be arranged in columns and masses, but there was much cellular pleomorphism and there were many tumour giant cells (Fig. 2).

Case 4.-Female aged 66 years. Death from liver failure.

Liver.-Weight 4,000 g. The right lobe contained numerous closely packed pale tumour nodules, the left lobe fewer but similar masses. Both hepatic veins were distended with tumour tissue. The small amount of surviving liver was cirrhotic.

Microscopically the tumour was a predominantly anaplastic and undifferentiated carcinoma (Fig. 3), with some areas showing a cholangiomatous glandular pattern (Fig. 4).

Case 5.-Male aged 62 years. Death from liver failure due to haemochromatosis.

Liver.-Weight $3,324 \mathrm{~g}$. The central part of the organ contained many nodules of pale tumour, the largest $2 \mathrm{~cm}$. in diameter. Tumour in the hepatic veins extended into the inferior vena cava and the portal vein was thrombosed. The remaining liver tissue showed the typical changes of haemochromatosis.

Microscopically the tumour was predominantly an undifferentiated hepatocellular carcinoma (Fig. 5), but with areas of tumour consisting of small structures resembling bile ducts (Fig. 6).

Case 6.-No clinical details available.

Liver.-Approximately normal size and containing numerous nodules of pale tumour, the largest $1 \mathrm{~cm}$. in diameter. The remaining liver tissue showed the typical changes of haemochromatosis.

Microscopically the tumour contained poorly differentiated hepatocellular carcinoma (Fig. 7) and cholangiomatous areas consisting of tubules lined by cuboidal and columnar epithelium (Fig. 8).

Case 7.-Male aged 58 years. Death from liver failure and bronchopneumonia.

Liver.-Weight $1,840 \mathrm{~g}$. A mass of pale tumour, $15 \mathrm{~cm}$. in diameter, was present in the lower part of the left lobe and projected from it. Smaller nodules of similar tumour surrounded the main mass, and the remainder of the liver was deeply bile stained and showed coarse irregular fibrosis. A tongue of tumour extended from the main mass into the left hepatic and common bile ducts.

Microscopically the tumour was an undifferentiated hepatocellular carcinoma with areas of differentiation into tubules suggestive of small bile ducts (Fig. 9). The surrounding liver tissue showed the changes of biliary cirrhosis.

Case 8.-Female aged 44 years. Death from suppurative cholangitis and liver failure.

Liver.-Weight unknown, but the organ was greatly enlarged and bile stained. Ramifying 


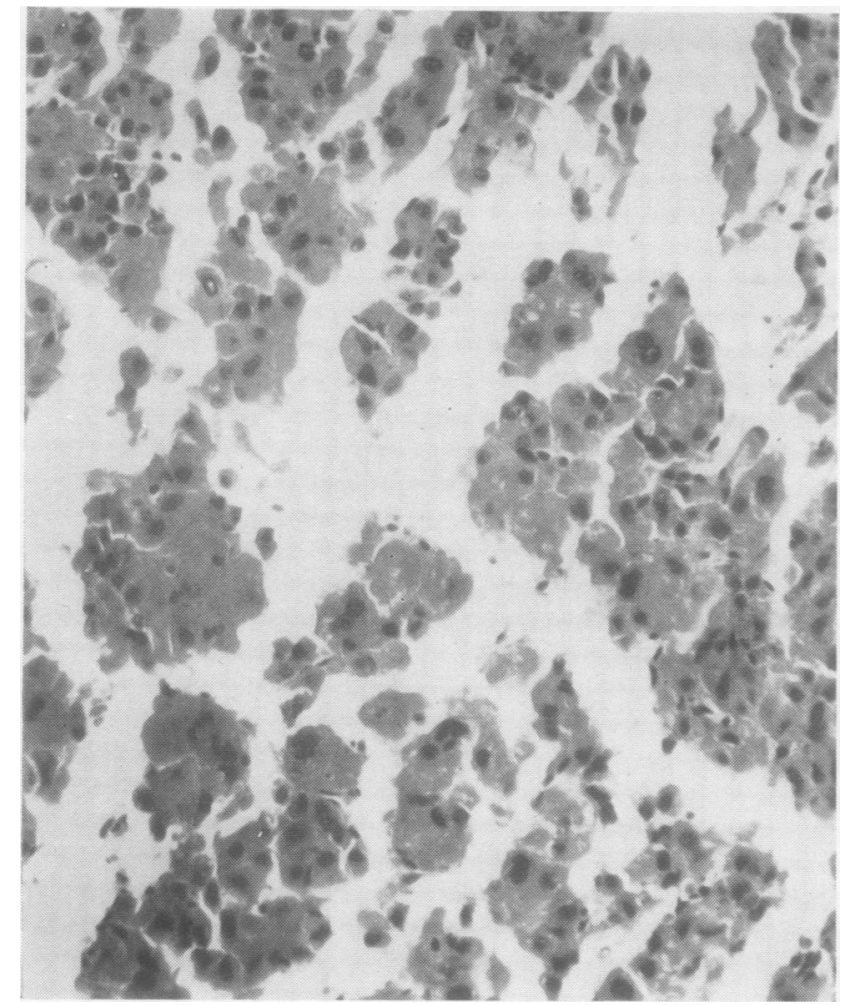

FIG. 7.-Case 6: Poorly differentiated hepatocellular carcinoma. Haematoxylin and eosin $\times 200$.

masses of pale tumour radiated from the porta hepatis throughout the liver, and many small abscesses were present.

Microscopically the tumour was a well-differentiated, mucus-producing cholangiocellular carcinoma. consisting of large glandular spaces lined by cuboidal epithelium (Fig. 10).

The details of the cases are summarized in the following table:

\begin{tabular}{|c|c|c|c|c|}
\hline Case & Sex & Age & Cirrhosis & Tumour \\
\hline \multirow{4}{*}{$\begin{array}{l}1 \\
2 \\
3 \\
4 \\
5 \\
6 \\
7 \\
8\end{array}$} & \multirow{3}{*}{$\begin{array}{l}\text { Female } \\
\text { Male } \\
\text { Female } \\
\text { Male }\end{array}$} & \multirow{3}{*}{$\begin{array}{l}85 \\
67 \\
62 \\
66 \\
62\end{array}$} & Present & Hepatocellular \\
\hline & & & Abšent & \\
\hline & & & $\begin{array}{l}\text { Present } \\
\text { Haemochromatosis }\end{array}$ & $\begin{array}{l}\text { Cholangioma } \\
\text { Mixed }\end{array}$ \\
\hline & $\begin{array}{l}\text { Male } \\
\text { Female }\end{array}$ & $\begin{array}{l}\overline{58} \\
44\end{array}$ & $\begin{array}{l}\text { Present } \\
\text { Absent }\end{array}$ & Cholangioma \\
\hline
\end{tabular}

\section{Discussion}

Diverse views have been held on the histogenesis of primary hepatic carcinomata.

Milne (1909) believed that hepatic carcinomata arose from either liver cells or bile duct epithelium and that, even though liver cells and bile ducts were related embryologically, the two types of tumour were quite distinct. Yamagiwa (1911) and Beattie and Donaldson (1912) also recognized only two varieties, arising from liver parenchyma and bile duct epithelium respectively.

The existence of apparently mixed tumours, originating from both liver cells and bile ducts, was postulated by Warvi (1944) and Allen and Lisa (1949). Kinosita (1937) induced hepatic carcinomata experimentally in rats by the administration of butter yellow. He described 18 hepatomas and 16 mixed hepatomas and cholangiomas. No pure cholangiomas were produced, cholangiomatous tissue being found only with hepatomas. He therefore postulated that both liver cells and bile duct epithelium could undergo simultaneous neoplasia, although he decided later (Kinosita. 1940) that all primary liver carcinomata originated from liver parenchyma.

A case described by Koster and Kasman (1932), in which the cirrhotic liver of a 60 year-old male contained multiple apparently discrete and separate hepatomas and cholangiomas, suggests that liver parenchyma and bile duct epithelium may undergo simultaneous tumour formation.

Ewing (1940) believed that pure hepatomas and cholangiomas arose from liver cells and bile duct epithelium respectively, and that the mixed tumours either had a dual origin or had arisen from liver cells which had earlier assumed the characteristics of bile ducts. MacCallum (1904) stated that regenerating liver cells may assume. possibly temporarily, the appearance of bile ducts. and Muir (1908) described the formation of tubular structures from liver cells in a healing laceration of the liver. The latter quotes Hess (1890) as reporting that the cells of similar structures contained glycogen though less than the surrounding liver parenchyma. Muir (1908) also considered that, although true bile duct proliferation took place in cirrhosis of the liver, structures resembling bile ducts were also formed from liver cells. Mallory (1911), in a study of pre-cirrhotic liver lesions, also described the formation of tubular structures or pseudo bile ducts from liver cells, and his description of these suggests that their cells were smaller and darker than those described by MacCallum (1904) and by Muir (1908) in his healing liver laceration.

Opie (1944) produced cirrhosis and primary liver carcinomata experimentally in animals and 


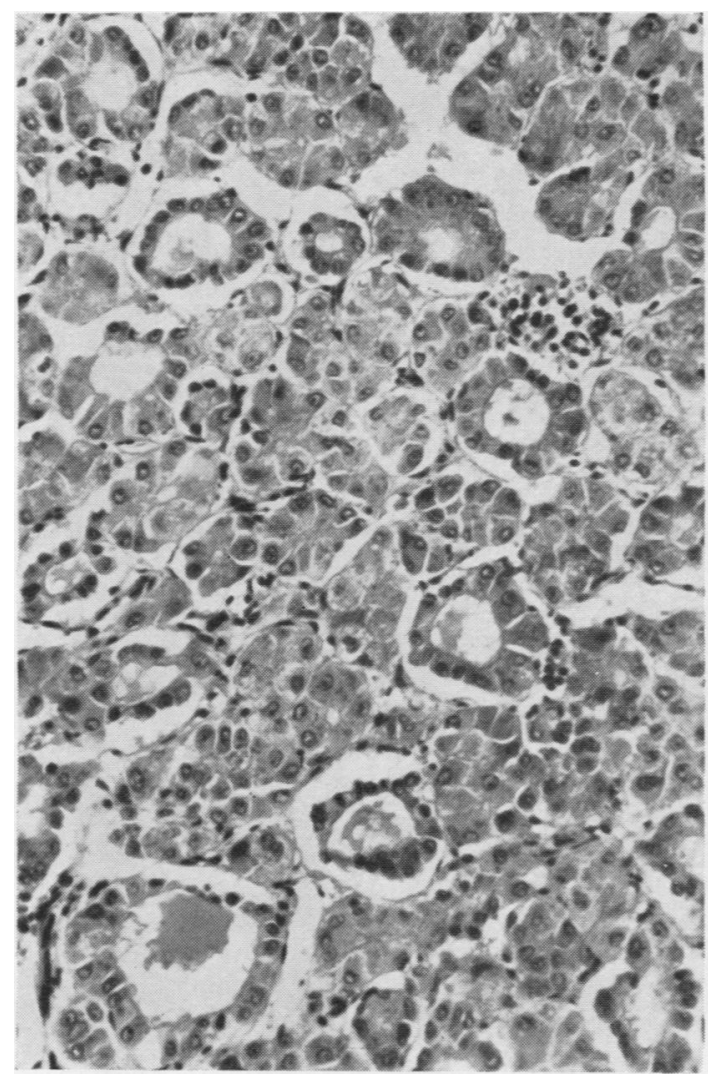

FIG. 8.-Case 6: Cholangiocellular area. Haematoxylin and eosin $\times 200$.

described the formation of pseudo bile ducts around both biliary tracts and central veins, in which latter site they could only have arisen from liver cells. His description leaves no doubt that these new or pseudo bile ducts were everywhere derived from liver cells.

A careful search around nodules of hyperplastic liver cells in cirrhotic livers revealed the formation of pseudo bile ducts, of varying size, from regenerating liver cells (Fig. 11), and glycogen could be demonstrated in their cells, albeit with difficulty.

There is, therefore, abundant evidence that liver cells can give rise to tubular structures of varying appearance, many of which resemble bile ducts, and Mansens (1954) considers that this is due to dedifferentiation of liver cells in the presence of growing mesenchyme.

The first three cases reported here are hepatomas of progressing anaplasia and undifferentiation. The last case (Case 8 ) is a classical, welldifferentiated cholangioma, while Case 4 is a cholangioma with large anaplastic and undifferentiated areas. Three examples of apparently mixed

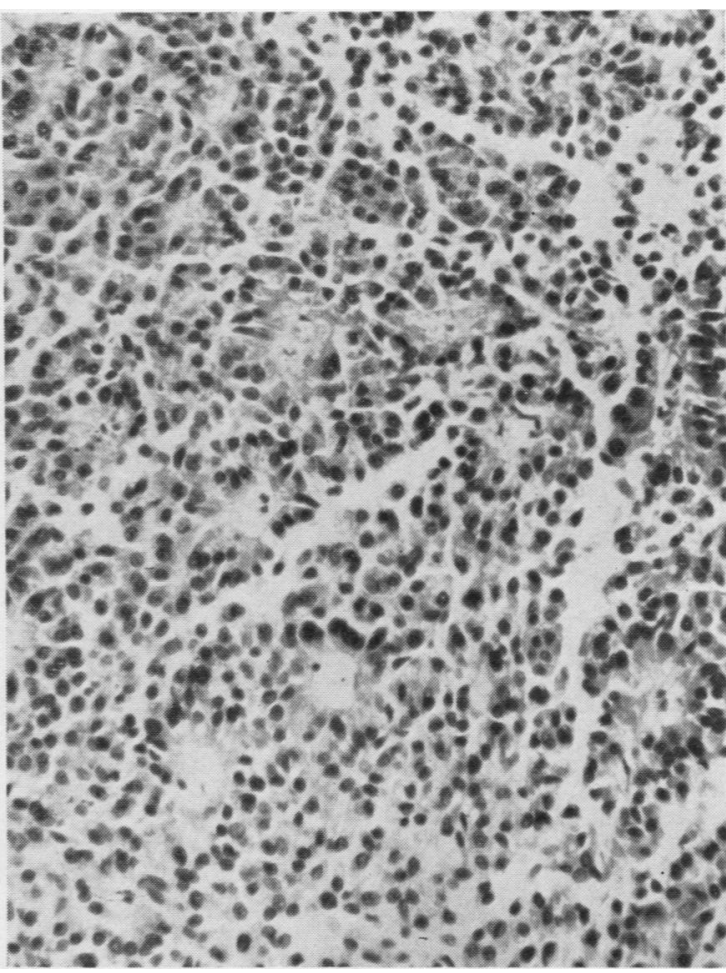

FIG. 9.-Case 7: Area showing tubular structures resembling small bile ducts. Haematoxylin and eosin $\times 200$.

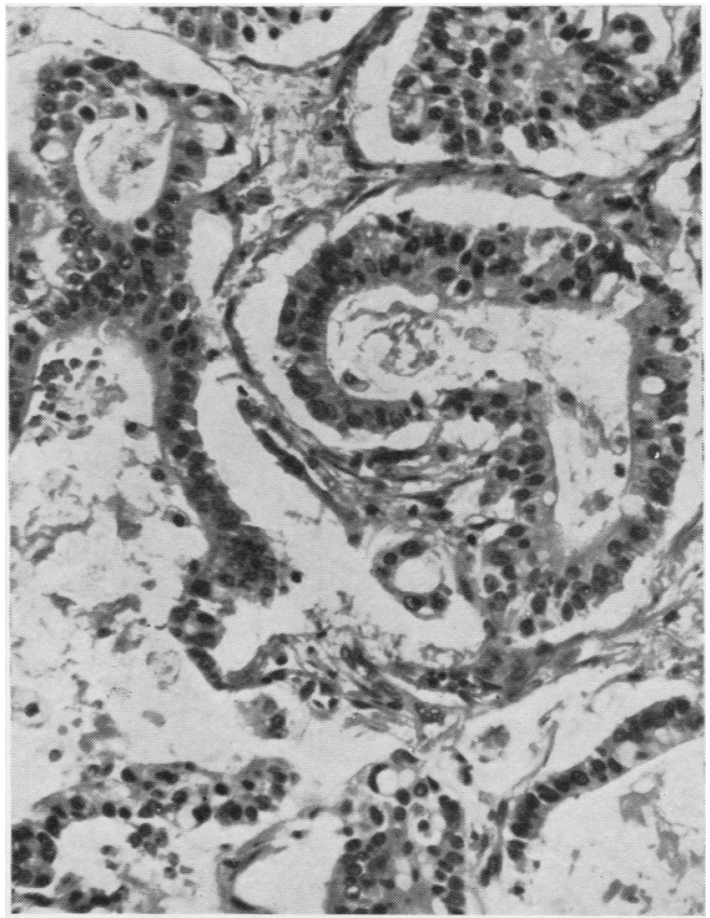

FIG. 10.-Case 8. Well-differentiated cholangiocellular carcinoma. Haematoxylin and eosin $\times 200$. 


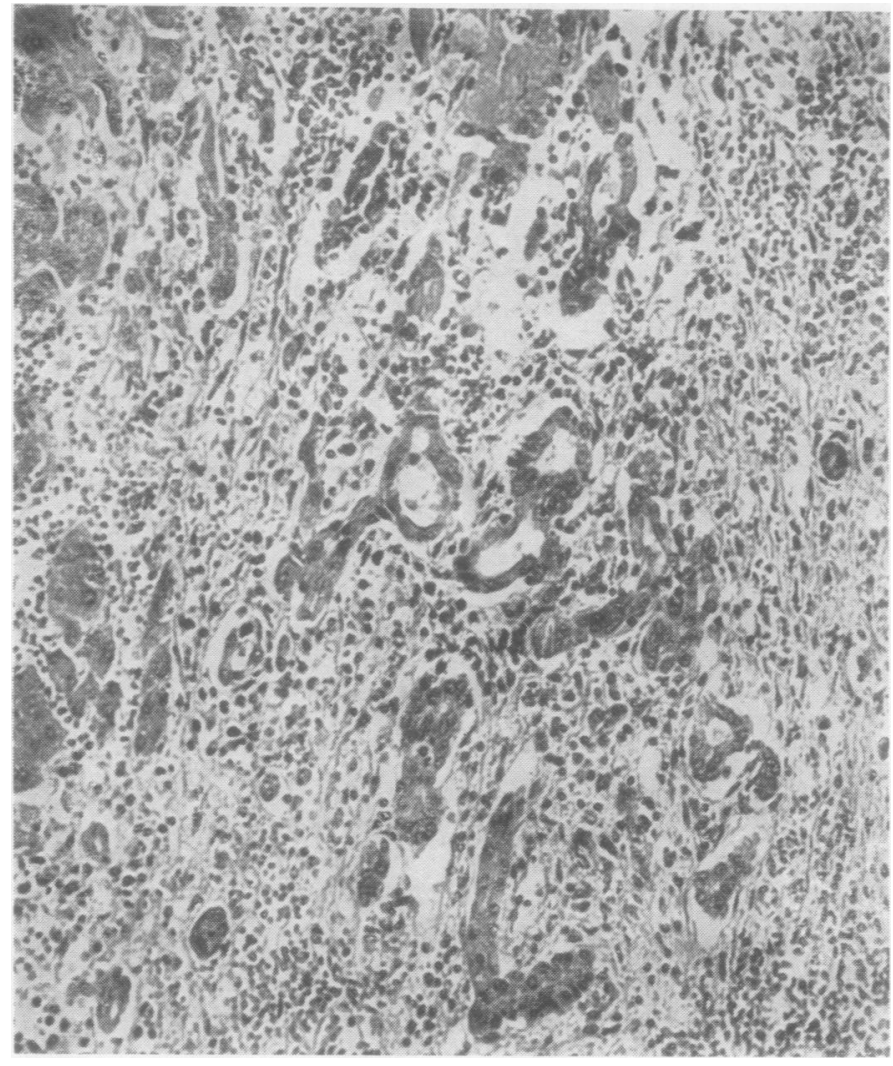

FIG. 11.-Pseudo bile ducts being formed from liver cells in a cirrhotic liver. Haematoxylin and eosin $\times 200$.

tumours (Cases 5, 6, and 7) consist of hepatocellular tissue compounded with cholangioma-like areas containing acini, which resemble small bile ducts.

The cholangioma-like elements in Case 6 (Fig. 8 ) closely resemble the structures described by Muir (1908) in a healing liver laceration, and by MacCallum (1904). The same elements of Case 5 (Fig. 6) are strikingly similar to the pseudo bile ducts described by Mallory (1911) and by Opie (1944) and those illustrated in Fig. 11.

Glandular structures of varying size resembling bile ducts have been described in tumours which were considered to be pure hepatomas (Loesch, 1939; Evans, 1956). Warvi (1944), although adhering to the concept of mixed tumours, admitted that hepatomas may contain areas of pseudo-biliary structure giving a false impression of hepatocholangioma, while Hou (1956) described hepatoma-like areas in hepatic carcinomata which, he believed, had arisen almost certainly from bile ducts.
Although simultaneous neoplasia of liver cells and bile duct epithelium may occur, the conclusion must be reached that only two varieties of primary hepatic carcinoma exist, namely hepatomas and cholangiomas. The apparently mixed type are usually hepatomas with pseudobiliary differentiation, but may be cholangiomas containing anaplastic areas morphologically resembling hepatomas.

\section{Summary}

Eight cases of primary hepatic carcinoma, three hepatocellular, two cholangiocellular, and three of apparently mixed variety, are described.

An examination of these and previously reported cases, as well as experimental data, indicate that both hepatocellular and cholangiocellular carcinoma may mimic each other and that mixed tumours, arising from both liver cells and bile duct epithelium, must be extremely rare. if they occur at all.

We wish to thank Mr. E. A. Wallington, F.I.M.L.T., and the technical staff of the Department of Morbid Anatomy for their assistance, and Mrs. P. Thomas for the photomicrographs.

\section{REFERENCES}

Allen, R. A., and Lisa, J. R. (1949). Amer. J. Path., 25, 647.

Beattie, J. M., and Donaldson, R. (1912). J. Path. Bact., 17, 32.

Campbell, J. G. (1949). Brit. J. Cancer, 3, 198.

Counseller, V. S., and McIndoe. A. H. (1926). Arch. intern. Med. 37, 363.

Cunningham, R. M. (1943). Bull. Sch. Med. Maryland, 28, 61.

Evans, R. W. (1956). Histological Appearances of Tumours. Livingstone, Edinburgh.

Ewing, J.(1940). Neoplastic Diseases, 4th ed. Saunders, Philadelphia.

Fried, B. M. (1924). Amer. J. med., Sci., 168, 241.

Gustafson, E. G. (1937). Ann. intern. Med., 11, 889.

Hess, K. (1890). Virchows Arch. path. Anat., 121, 154

Hou, P. C. (1956). J. Path. Bact..72, 239.

Hoyne, R. M., and Kernohan, J. W. (1947). Arch. intern. Med., 79, 532 .

Karsner, H. T. (1911). Ibid., 8, 238.

Kinosita, R. (1937). Trans. Soc. path. jap., 27, 665.

(1940). Yale J. Biol. Med., 12, 287.

Koster, J., and Kasman, L. P. (1932). Amer. J. Surg., 17, 237.

Loesch, J. (1939). Arch. Path. (Chicago), 28, 223

MacCallum, W. G. (1904). J. Amer. med. Ass., 43, 649.

Mallory, F.'B. (1911) Bull. Johns Hopk. Hosp., 22, 69.

Mallory, F. B. (1911). Bull. Johns Hopk. Hosp

Mansens, B. J. (1954). J. Path. Bact.

Muir, R. (1908). Ibid., 12, 287.

Opie, E. L. (1944). J. exp. Med., 80, 231

Pirie, J. H. H. (1921). Med.J.S.Afr., 17, 87.

Warvi, W. N. (1944). Arch. Path. (Chicago), 37, 367.

Wilbur, D. L., Wood, D. A., and Willett, F. M. (1944). Ann. intern. Med., 20, 453.

Yamagiwa, K. (1911). Virchows Arch. path. Anat., 206, 437. 